\title{
Water-resistant and high oxygen-barrier nanocellulose films with interfibrillar cross-linkages formed through multivalent metal ions
}

Michiko Shimizu, Tsuguyuki Saito, Akira Isogai*

Department of Biomaterials Science, Graduate School of Agricultural and Life Sciences, The University of Tokyo, Tokyo 113-8657 Japan

*Corresponding author at: Department of Biomaterials Science, Graduate School of Agricultural and Life Sciences, The University of Tokyo, Tokyo 113-8657 Japan E-mail address: aisogai@mail.ecc.u-tokyo.ac.jp (A. Isogai)

\begin{abstract}
Once-dried 2,2,6,6-tetramethylpiperidine-1-oxyl (TEMPO)-oxidized cellulose nanofibril (TOCN) films with sodium carboxylate groups (TOCN-COONa) were soaked in aqueous $\mathrm{MgCl}_{2}, \mathrm{CaCl}_{2}, \mathrm{AlCl}_{3}$ and $\mathrm{FeCl}_{3}$ solutions to change the counterion to TOCNs-COOM films (M: metal ion). Dry TOCN-COOM films had high Young's moduli (11-20 GPa) and tensile strength (170-280 MPa). In particular, the wet TOCN films with aluminum and iron (III) carboxylates had high Young's moduli and tensile strengths of $\sim 3 \mathrm{GPa}$ and 30-40 $\mathrm{MPa}$, respectively, even at water contents of $\sim 470 \%$. Moreover, the dry TOCN films with calcium and aluminum carboxylates had extremely low oxygen permeabilities of 0.08 and $0.15 \mathrm{~mL}$ $\mu \mathrm{m} \mathrm{m}^{-2}$ day $^{-1} \mathrm{kPa}^{-1}$, respectively, even at $80 \%$ relative humidity, which are outstanding values compared to those of other films reported previously. These results are explained in terms of the high water resistance of the films, which is caused by the formation of interfibrillar cross-linkages through multivalent metal ions.
\end{abstract}

(C) 2015. This manuscript version is made available under the Elsevier user license http://www.elsevier.com/open-access/userlicense/1.0/ 
Keywords: Nanocellulose, TEMPO, Water resistance, Oxygen barrier, Ion exchange

\section{Introduction}

The films constituted of nanofibrillated celluloses show excellent physical properties such as high modulus, high tensile strength and low oxygen permeability [1-3]. Nanocellulose-containing films are thus promising candidates for packaging films for food and pharmaceutical products or as the substrates of electronic devices [4-7]. However, the properties of these films are impaired by humidity, because they have abundant hydroxyl groups and are therefore hydrophilic. Water molecules preferentially adsorb on cellulose nanofibril surfaces, resulting in the swelling of the films. This hydrophilic nature of nanocelluloses causes serious problems in practical applications, when nanocellulose films and nanocellulose-containing composites are used under humid conditions or in water.

Water molecules adsorbing onto the hydroxyl groups plasticize nanocellulose films by partial cleavage of interfibrillar hydrogen bonds that form under dry conditions $[8,9]$. When these interfibrillar hydrogen bonds are cleaved by water or under humid conditions, the stiffness and tensile strength of the nanocellulose films are drastically decreased. This also causes the oxygen permeability to increase as the relative humidity $(\mathrm{RH})$ is increased $[10,11]$. Oxygen can easily penetrate water- or moisture-containing films, and it becomes more diffusible when water molecules are present between the nanofibrils. This increase in the mobility of oxygen molecules accelerates the oxygen permeability through the films under humid conditions [12].

Thus, improving the water or moisture resistance of hydrophilic nanocelluloses is a challenge of interest in practical applications. The water resistance of films is often evaluated by the wet tensile strength, which is measured in water-containing films prepared by soaking 
once-dried films in water for a certain amount of time [13-17]. The wet tensile strength of nanocellulose films has been improved by making composites with poly(vinyl alcohol), starch, chitosan or carboxymethyl cellulose, although these composite materials need multiple and time-consuming procedures for their preparations [13-17]. Chemical modifications of the cellulose hydroxyl groups have been tried to add hydrophobicity to nanocellulose films. However, these modifications often decrease the crystallinity of nanocelluloses, resulting in a decrease in their mechanical performance $[18,19]$. Large amounts of chemicals and organic solvents are often required to introduce sufficient amounts of hydrophobic ester or ether groups to the hydroxyl groups of nanocellulose, which is not environmentally friendly.

When 2,2,6,6-tetramethylpiperidine-1-oxyl (TEMPO)-mediated oxidation is applied to wood celluloses suspended in water, completely individualized TEMPO-oxidized cellulose nanofibrils (TOCNs) with homogeneous widths of $3 \mathrm{~nm}$ and lengths of $>300 \mathrm{~nm}$ are obtained as aqueous TOCN dispersions [2]. Sodium carboxylate groups are densely, regularly and position-selectively present on the crystalline TOCN surfaces. The surface modification of these carboxylate groups of TOCNs has been reported to increase the hydrophobicity of the TOCNs [20-23]. Surfactants have amphiphilic chemical structures, so the adsorption of cationic surfactants on anionic TOCN surfaces often plays an important role in efficiently making TOCNs hydrophobic without damaging the crystalline nanofibril structures. However, the self-standing films of surface-modified TOCNs have low mechanical performance, probably because the formation of interfibrillar hydrogen bonds is partially prevented by the introduction of hydrophobic surfactants onto the TOCN surfaces.

In our previous study, hydrophobic nanocellulose films with quaternary alkylammonium (QA) carboxylate groups were prepared from aqueous TOCN-COOQA dispersions [24]. The TOCN-COOQA films with tetrabutylammonium carboxylate groups showed water contact angles of $\sim 100^{\circ}$ and higher mechanical performance than those of commercially available 
synthetic polymer films. However, the oxygen permeability of the TOCN-COOQA films increased with RH. This is probably because the ionic bonds of the QA carboxylate groups are still hydrophilic, and water molecules adsorbing on the ammonium carboxylate groups in the TOCN-COOQA films could accelerate the diffusivity of oxygen molecules inside the films.

In this study, we prepared TOCN films with metal carboxylate groups, TOCNs-COOM (M: metal ion), to improve their water resistance. The TOCN-COOM films with interfibrillar cross-linkages through multivalent metal ions had high wet tensile strengths and low oxygen-permeabilities even under humid conditions, depending on the metal ions introduced.

\section{Experimental}

\subsection{Materials}

A never-dried softwood bleached kraft pulp (SBKP, Nippon Paper Industries, Japan) was used as the original cellulose. Sodium chloride $(\mathrm{NaCl})$, magnesium chloride $\left(\mathrm{MgCl}_{2}\right)$, calcium chloride $\left(\mathrm{CaCl}_{2}\right)$, aluminium chloride $\left(\mathrm{AlCl}_{3}\right)$ hexahydrate, iron (III) chloride $\left(\mathrm{FeCl}_{3}\right)$ hexahydrate and other chemicals were laboratory grade (Wako Pure Chemicals, Japan) and used as received.

\subsection{Preparation of TOCN-COONa films}

Aqueous $0.1 \% \mathrm{w} / \mathrm{v}$ TOCN dispersions with sodium carboxylate groups (TOCN-COONa) were prepared according to our previous report [25]. In brief, SBKP was oxidized with TEMPO/ $\mathrm{NaBr} / \mathrm{NaClO}$ system in water at $\mathrm{pH} 10$. After post-oxidation with $\mathrm{NaClO}_{2}$ in water at

$\mathrm{pH} 4.8$, the resulting TEMPO-oxidized cellulose had a carboxylate content of $1.6 \mathrm{mmol} \mathrm{\textrm {g } ^ { - 1 }}$ and a viscosity-average degree of polymerization of 500 [26]. The TEMPO-oxidized cellulose/water slurry was mechanically disintegrated using a double-cylinder-type homogenizer (Microtec NS-56 Physcotron, Japan) for $1 \mathrm{~min}$ and an ultrasonic homogenizer (Nihon Seiki US-300T, Japan) at $300 \mathrm{~W}$ for $8 \mathrm{~min}$, to obtain a $0.1 \% \mathrm{w} / \mathrm{v}$ aqueous TOCN 
dispersion. An unfibrillated fraction $(<10 \%)$ present in the dispersion was removed by centrifugation at $12000 \mathrm{~g}$ for $15 \mathrm{~min}$, and the supernatant was used as the TOCN-COONa dispersion. The TOCN-COONa dispersion was poured into poly(styrene) Petri dishes and dried at $40{ }^{\circ} \mathrm{C}$ for 3 days. The resulting TOCN-COONa films with thicknesses of $15 \pm 1 \mu \mathrm{m}$ were conditioned at $23^{\circ} \mathrm{C}$ and $50 \% \mathrm{RH}$ before use.

\subsection{Preparation of TOCN-COOM films}

The TOCN-COONa films $\left(25-30 \mathrm{mg}\right.$ and $7 \times 7 \mathrm{~cm}^{2}$ each) were soaked in aqueous $0.1 \mathrm{M}$ $\mathrm{NaCl}, \mathrm{HCl}, \mathrm{MgCl}_{2}, \mathrm{CaCl}_{2}, \mathrm{AlCl}_{3}$ or $\mathrm{FeCl}_{3}$ solutions (100 mL each) for $2 \mathrm{~h}$. The original dried and conditioned TOCN-COONa film without any soaking treatment was coded as "original TOCN-COONa", and the TOCN films after soaking in dilute $\mathrm{HCl}$ or metal chloride solutions were coded as TOCN-COOH, TOCN-COONa, TOCN-COOCa, TOCN-COOMg, TOCN-COOAl and TOCN-COOFe, respectively. These TOCN-COOM films were soaked in fresh distilled water three times to ensure they were washed, placed on silicone rubber plates, and dried at $23{ }^{\circ} \mathrm{C}$ and $50 \% \mathrm{RH}$ for 2 days.

\subsection{Analyses}

The amounts of sodium and chloride ions in the TOCN-COOM films were determined on an energy-dispersive X-ray fluorescence analyzer (XRF) (Shimadzu EDX-8000, Japan). Fourier transform infrared (FTIR) and light transmittance spectra of the films were obtained using a FTIR spectrometer (JASCO FT/IR-6100, Japan) and a UV-vis-NIR spectrometer (JASCO V670, Japan), respectively. The film thicknesses were calculated from the interference patterns in the transmittance spectra according to a previously reported method $[24,27]$. The film densities were calculated from the volumes and weights of the dry films after conditioning at $23{ }^{\circ} \mathrm{C}$ and $50 \% \mathrm{RH}$. The moisture contents of the conditioned films were

calculated from the weights before and after heating at $105^{\circ} \mathrm{C}$ for $3 \mathrm{~h}$. Tensile test on dry films was carried out at $23{ }^{\circ} \mathrm{C}$ and $50 \% \mathrm{RH}$ using a tensile tester (Shimadzu EZ-TEST, Japan) 
equipped with a $500 \mathrm{~N}$ load cell. The film specimens were $3 \mathrm{~mm}$ wide and $40 \mathrm{~mm}$ long. At least five specimens were measured for each sample with a span length of $15 \mathrm{~mm}$ at a rate of $1.0 \mathrm{~mm} \mathrm{~min}^{-1}$. Oxygen permeability $\left(\mathrm{P}-\mathrm{O}_{2}\right)$ of the TOCN films was measured at $23{ }^{\circ} \mathrm{C}$ and at 46, 65 and $80 \%$ RH, using an apparatus for determination of oxygen transmission rates (MOCON OX-TRAN 2/21, Modern Control Inc., USA) according to a standard method (ASTM D-3985) [6,24].

The TOCN-COOM films, which were prepared by soaking the original TOCN-COONa film in aqueous $\mathrm{HCl}$ or metal chloride solutions, and successive washing with water, were soaked in fresh water for $1 \mathrm{~h}$ (without drying), and the wet films were picked up and excess water was removed with blotting paper. The water contents of the wet films were calculated from the weights before and after soaking in water. Wet tensile test was carried out for the water-containing and swollen films using the same apparatus as above at a span length of 10 $\mathrm{mm}$ according to TAPPI T 456 om-87 [28]. The thickness of the wet films was measured using a micrometer (Mitutoyo CLM1-15QM, Japan).

\section{Results and discussion}

\subsection{Structures of TOCN-COOM films}

In the present study, the counterions of the carboxylate groups on the TOCN surfaces of the original TOCN-COONa film were exchanged with $\mathrm{H}^{+}$and/or metal ions by soaking the original TOCN-COONa film in dilute $\mathrm{HCl}$ or metal chloride solutions followed by washing with fresh water and drying. Neither sodium nor chloride ions were detected in any of the ion-exchanged TOCN-COOH nor TOCN-COOM films by XRF (Figure 1). When the original TOCN-COONa film was soaked in aqueous $\mathrm{NaCl}$ solution, the washed TOCN-COONa film contained no chloride ion. Thus, the washing procedure of the soaked films with water used in this study is sufficient to completely remove any salt components physically trapped in the 
wet films. When the original TOCN-COONa film was soaked in each metal chloride solution, only the corresponding metal signal was detected in the XRF spectrum (Figure 1). Quantitative analysis of the metal ions present in the films was, however, difficult because of lack of suitable standard samples containing known amounts of metal ions. Nevertheless, we can conclude from the above results that almost all sodium ions in the original TOCN-COONa film were exchanged to $\mathrm{H}^{+}$or the designated multivalent metal ions by the simple procedure used in this study. Moreover, these results show that the cationic and multivalent metal ions introduced into TOCN-COOM films had no anionic chloride ions as counterions.
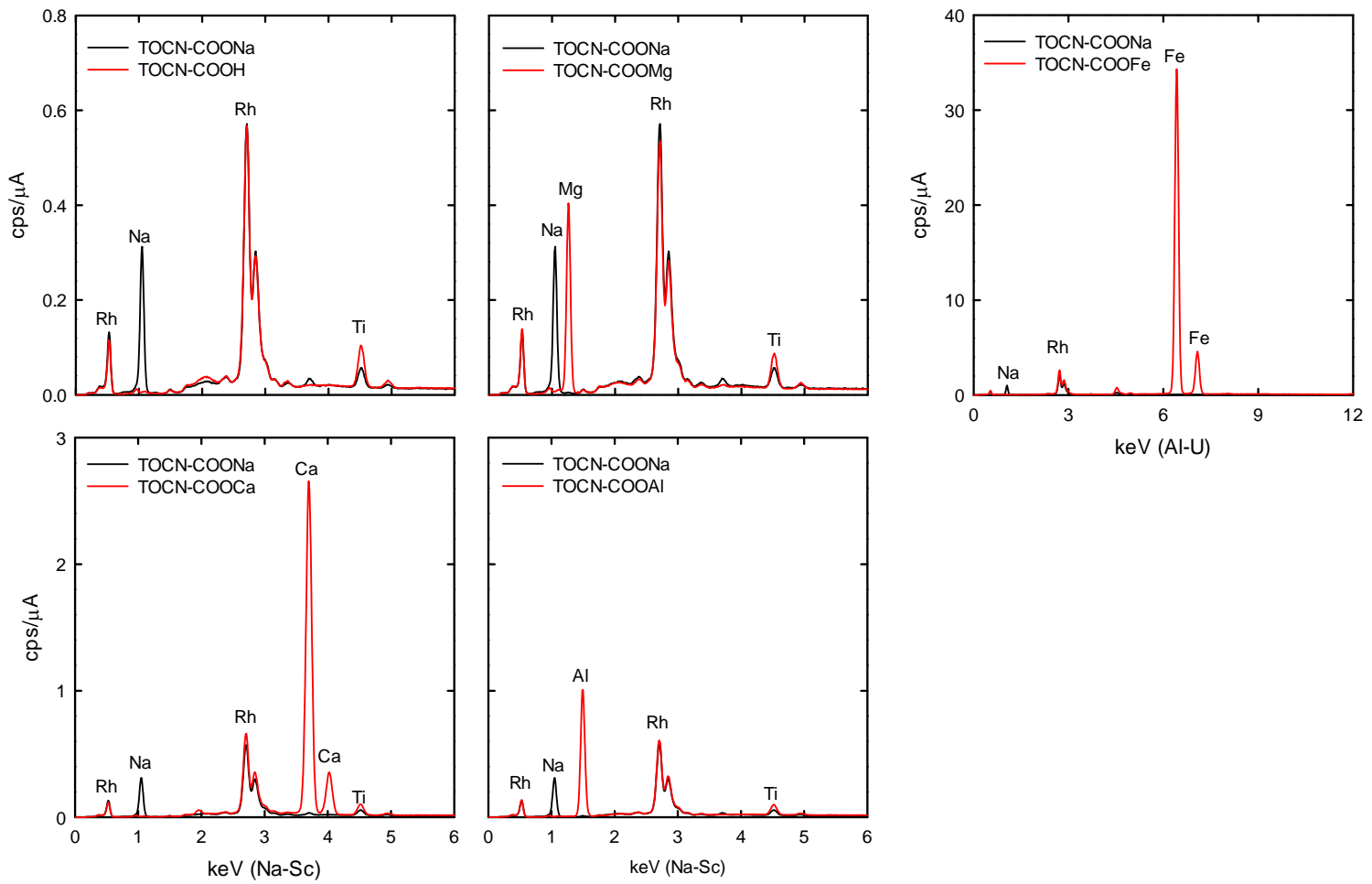

Fig. 1. XRF spectra of the original TOCN-COONa and ion-exchanged TOCN-COOM films. The peaks due to Rh and $\mathrm{Ti}$ are due to the XRF detector.

The FTIR spectra of the TOCN-COOCa and TOCN-COOMg films had no absorption band at $\sim 1720 \mathrm{~cm}^{-1}$, which could be assigned to protonated carboxyl groups (Figure 2). Because these films contained neither sodium nor chloride ion, they must have exclusively the 
metal carboxylate structures of $(\mathrm{TOCN}-\mathrm{COO})_{2} \mathrm{Ca}$ and $(\mathrm{TOCN}-\mathrm{COO})_{2} \mathrm{Mg}$, respectively, without the presence of TOCN-COOCaCl or TOCN-COOMgCl $[29,30]$. The TOCN-COOAl and TOCN-COOFe films, however, had not only the $\mathrm{C}=\mathrm{O}$ absorption band at $\sim 1600 \mathrm{~cm}^{-1}$ but also the band at $1720 \mathrm{~cm}^{-1}$ in the FTIR spectra, showing that these films have both metal carboxylate structures and some protonated carboxyls [22,25].

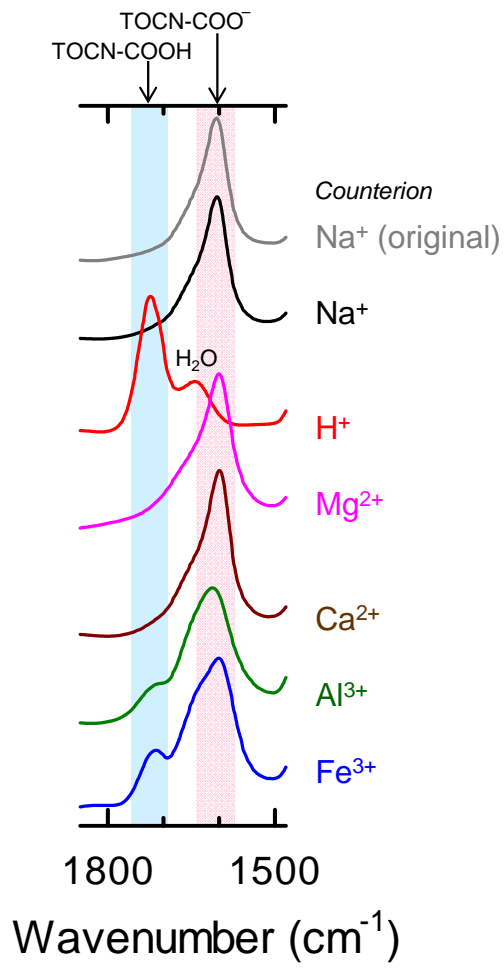

Fig. 2. FTIR spectra of the original TOCN-COONa and ion-exchanged TOCN-COOM films.

Table 1 shows the $\mathrm{pH}$ values of the $0.1 \mathrm{M}$ aqueous metal chloride solutions, molar ratios of the protonated carboxyl/metal carboxylate groups in the TOCN-COOM films (calculated from the two $\mathrm{C}=\mathrm{O}$ peak areas in FTIR spectra), and densities and moisture contents of the dry films conditioned at $23{ }^{\circ} \mathrm{C}$ and $50 \% \mathrm{RH}$. The water contents of the wet films are also listed in this Table. The aqueous $0.1 \mathrm{M} \mathrm{AlCl}_{3}$ and $\mathrm{FeCl}_{3}$ solutions had low $\mathrm{pH}$ values of $\sim 3.0$ and $\sim 1.8$, respectively, whereas the $\mathrm{p} K_{\mathrm{a}}$ values of C6-carboxyl groups in TOCN-COOH are $\sim 3.6[25,31]$. Thus, it is reasonable that some carboxyl groups were protonated during soaking treatment, 
and remained as the TOCN-COOH-type structures in the TOCN-COOAl and TOCN-COOFe films even after washing with water.

Table 1. pH Values of the $0.1 \mathrm{M}$ Metal Chloride Solutions Used in the Ion-Exchange, Molar Ratios of TOCN-COOH/TOCN-COOM in the TOCN-COOM Films, Their Densities and Moisture Contents at $23{ }^{\circ} \mathrm{C}$ and $50 \% \mathrm{RH}$, and Water Contents of the Wet Films.

\begin{tabular}{|c|c|c|c|c|c|c|}
\hline \multirow{2}{*}{$\begin{array}{l}\text { acid or salt } \\
\text { solution used in } \\
\text { soaking }\end{array}$} & \multirow{2}{*}{$\begin{array}{l}\mathrm{pH} \text { of } 0.1 \mathrm{M} \\
\text { salt solution }\end{array}$} & \multicolumn{2}{|c|}{ molar ratio of carboxyl groups (\%) } & \multirow{2}{*}{$\begin{array}{l}\text { film density } \\
\qquad\left(\mathrm{g} \mathrm{cm}^{-3}\right)^{a}\end{array}$} & \multicolumn{2}{|c|}{$\begin{array}{l}\text { moisture or water content } \\
(\%)\end{array}$} \\
\hline & & TOCN-COOH & TOCN-COOM & & dry film ${ }^{a}$ & wet film ${ }^{b}$ \\
\hline $\begin{array}{c}\text { original } \\
\text { TOCN-COONa } \\
\text { film }\end{array}$ & - & 0 & 100 & 1.53 & 11 & - \\
\hline $\mathrm{NaCl}$ & 5.5 & 0 & 100 & 1.56 & 12 & 11050 \\
\hline $\mathrm{HCl}$ & 1.0 & 100 & 0 & 1.51 & 9 & 590 \\
\hline $\mathrm{MgCl}_{2}$ & 6.6 & 0 & 100 & 1.44 & 13 & 579 \\
\hline $\mathrm{CaCl}_{2}$ & 5.5 & 0 & 100 & 1.68 & 14 & 445 \\
\hline $\mathrm{AlCl}_{3}$ & 3.0 & 11 & 89 & 1.44 & 13 & 473 \\
\hline $\mathrm{FeCl}_{3}$ & 1.8 & 27 & 73 & 1.58 & 11 & 318 \\
\hline
\end{tabular}

\footnotetext{
${ }^{a}$ Measured for once-dried and conditioned films at $23{ }^{\circ} \mathrm{C}$ and $50 \% \mathrm{RH}$.

${ }^{b}$ Measured after soaking the films in water for $1 \mathrm{~h}$.
}

The TOCN-COOCa film had a high density of about $1.7 \mathrm{~g} \mathrm{~cm}^{-3}$ at $23{ }^{\circ} \mathrm{C}$ and $50 \% \mathrm{RH}$, while the densities of the TOCN-COOMg and TOCN-COOAl films were as low as $\sim 1.4 \mathrm{~g}$ $\mathrm{cm}^{-3}$. The lowest moisture content of $9 \%$ was found for the TOCN-COOH film with completely protonated carboxylate groups, and other TOCN-COOM films had moisture contents of $11-14 \%$. The water content of the wet TOCN-COONa film was 20 times higher than those of the other TOCN-COOM films. All of the TOCN-COOM films were optically transparent and had high light-transmittances of $\sim 80 \%$ at $600 \mathrm{~nm}$, although the TOCN-COOFe film was colored because of the UV absorption due to $\mathrm{Fe}^{3+}$ ions in the film (Figure 3) [17,32] 


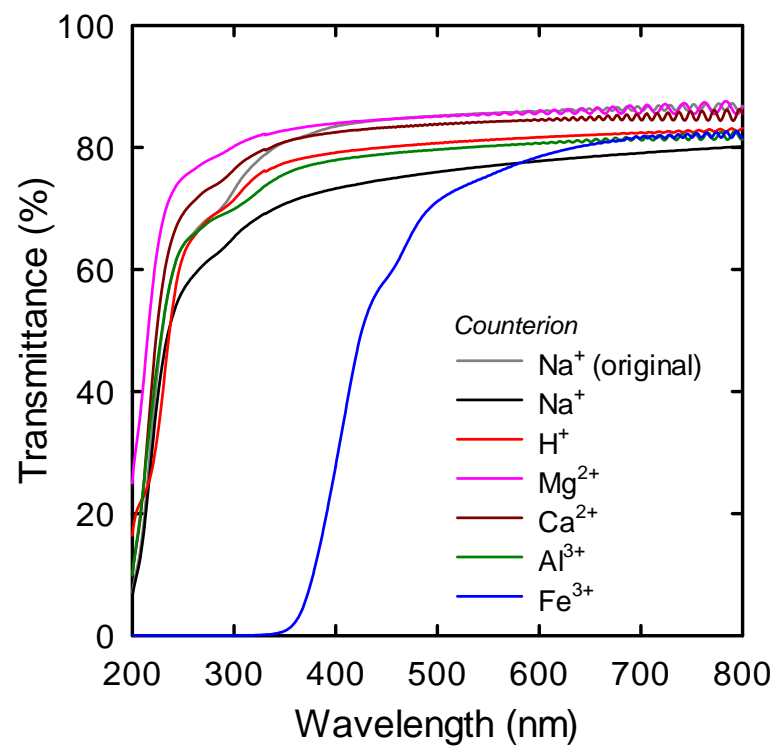

Fig. 3. Light transmittance spectra of the original TOCN-COONa and ion-exchanged TOCN-COOM films.

\subsection{Tensile properties of the dry TOCN-COOM films}

The stress-strain curves and tensile properties of the dried and conditioned TOCN-COOM films are shown in Figure 4. All the films had high Young's moduli of 11-20 $\mathrm{GPa}$, high tensile strength values of $170-280 \mathrm{MPa}$ and strain-to-failure values of $2.3-7.2 \%$. The TOCN-COONa film, which was prepared from the original TOCN-COONa film by soaking in aqueous $\mathrm{NaCl}$ solution and successive washing and drying, showed lower mechanical performance than the original TOCN-COONa film. The history of drying/water-swelling/re-drying process likely induced defects into the films [33].

The TOCN-COOMg and TOCN-COOAl films exhibited Young's moduli and tensile strengths higher than those of the original TOCN-COONa film. The stiffness of these TOCN-COOM films was improved probably by the formation of interfibrillar cross-linkages via $\mathrm{Mg}^{2+}$ and $\mathrm{Al}^{3+}$ ions. The lower electronegativity and smaller sizes of the $\mathrm{Mg}^{2+}$ and $\mathrm{Al}^{3+}$ ions than the other metal ions may have brought about superior stabilization of the ionic cross-linkages, resulting in the high mechanical performance of the once-dried and then 
conditioned films [34].
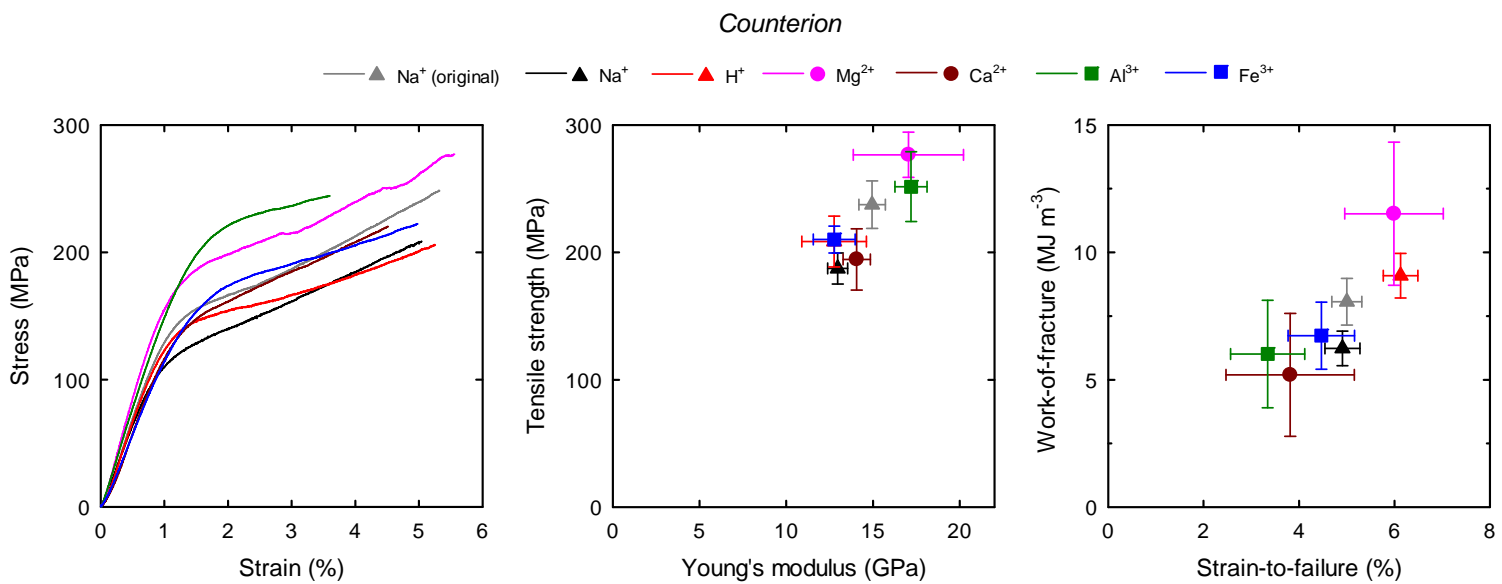

Fig. 4. Tensile properties of the once-dried and then conditioned TOCN-COOM films at $23{ }^{\circ} \mathrm{C}$ and 50\% RH: (a) stress-strain curves, (b) relationship between Young's modulus and tensile strength, and (c) relationship between strain-to-failure and work-of-fracture.

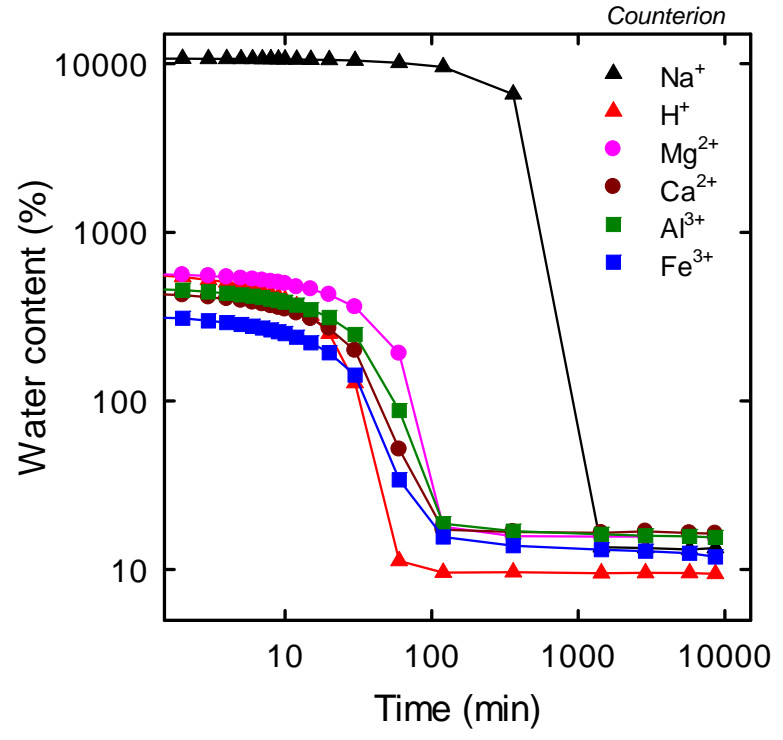

Fig. 5. Changes in water content of wet TOCN-COOM films, prepared by soaking the once-dried TOCN-COOM films in water, during drying at $23{ }^{\circ} \mathrm{C}$ and $50 \% \mathrm{RH}$.

\subsection{Tensile properties of the wet TOCN-COOM films}

The water contents of the wet TOCN-COOM films were measured after soaking the films 
in water for $1 \mathrm{~h}$ (Table 1). The wet TOCN-COOM films had water contents that ranged from 320 to $590 \%$, depending on the counterion. When the wet TOCN-COOM films were dried at $23{ }^{\circ} \mathrm{C}$ and $50 \% \mathrm{RH}$, the water content of each film, except for the TOCN-COONa film, gradually decreased for the first $30 \mathrm{~min}$, drastically decreased to $9-14 \%$ after $30-120 \mathrm{~min}$, and then reached a plateau value (Figure 5). The TOCN-COONa film retained its high water contents $>10000 \%$ for up to $10 \mathrm{~h}$ during the drying process because of its highly hydrophilic nature.
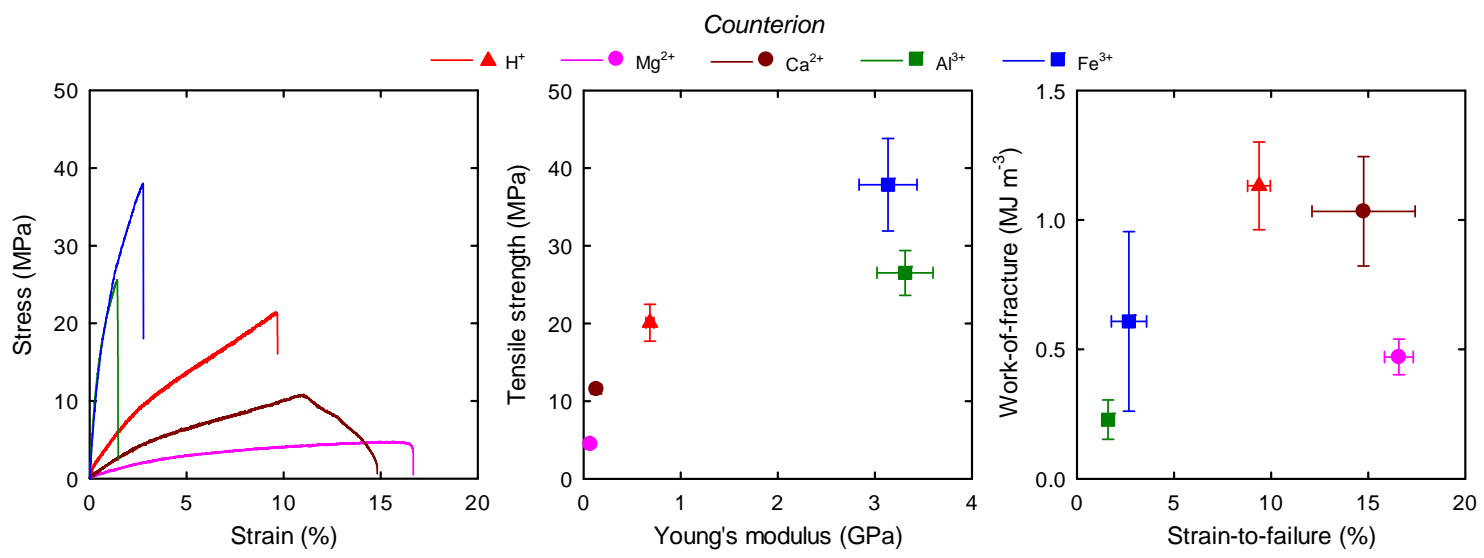

Fig. 6. Tensile properties of the wet TOCN-COOM films: (a) stress-strain curves, (b) relationship between Young's modulus and tensile strength, and (c) relationship between strain-to-failure and work-of-fracture. The water contents of the wet films are listed in Table 1.

Figure 6 shows the stress-strain curves and tensile properties of the wet TOCN-COOM films. The wet TOCN-COONa film could not be subjected to the wet tensile test, because in its water-swollen state, the film was too weak to be picked up [8]. The other TOCN-COOM films maintained their swollen film shapes during the tensile test. The wet TOCN-COOAl and TOCN-COOFe films had high Young's moduli and tensile strengths of 3.0-3.6 GPa and 24 $44 \mathrm{MPa}$, respectively. In contrast, the TOCN-COOMg and TOCN-COOCa films had low Young's moduli of $0.05-0.14 \mathrm{GPa}$, low tensile strengths of 4.2-12 $\mathrm{MPa}$ and high strains-to-failure of $12-17 \%$. 
A wet nanocellulose film with a high water content usually has a decreased tensile strength and increased strain-to-failure $[8,13-16,35]$. These properties are explained in terms of the plasticization induced by water. Therefore, it is reasonable that the wet TOCN-COOMg and TOCN-COOCa films had high strains-to-failure. However, the wet TOCN-COOAl and TOCN-COOFe films were extremely stiff, and their Young's moduli and tensile strengths were approximately three times higher than those of the wet TOCN-COOMg and TOCN-COOCa films, though all the films had high water contents of $320-470 \%$. These results show that trivalent ions such as $\mathrm{Al}^{3+}$ and $\mathrm{Fe}^{3+}$ can form interfibrillar cross-linkages stable to water in wet TOCN-COOM films [17,28,32]. Protonated carboxyl groups in the TOCN-COOH film can form inter- and intra-fibrillar hydrogen bonds [31], and thus have better mechanical performance than the wet TOCN-COOMg and TOCN-COOCa films.

\subsection{Oxygen permeability of TOCN-COOM films under humid conditions}

The $\mathrm{P}-\mathrm{O}_{2}$ values of all TOCN films increased as the $\mathrm{RH}$ was increased from $46 \%$ to $80 \%$ (Figure 7). However, the TOCN-COOCa and TOCN-COOAl films had extremely low $\mathrm{P}-\mathrm{O}_{2}$ values of 0.08 and $0.15 \mathrm{~mL} \mu \mathrm{m} \mathrm{m}^{-2}$ day $^{-1} \mathrm{kPa}^{-1}$, respectively, even at $80 \% \mathrm{RH}$. These values were significantly lower than those of previously reported nanocellulose films $[10,35-39]$; the $\mathrm{P}-\mathrm{O}_{2}$ values of nanofibrillated cellulose films containing $20 \%$ nanoclay (at $80 \% \mathrm{RH}$ ), partially C2/C3-dialcohol nanocellulose films (at $80 \% \mathrm{RH}$ ), wax-coated nanofibrillated cellulose films (at 97\% RH), and nanoclay-containing poly(vinyl alcohol) films (at 90\% RH) are 1.5, 5.5, 17,

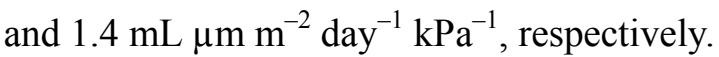

The $\mathrm{P}-\mathrm{O}_{2}$ values of regenerated cellulose, nanocellulose and hydrophilic synthetic polymer films are primarily explained in terms of pore sizes, pore size distributions and the water content of the films at various RHs [35,40-45]. In the case of hydrophilic poly(vinyl alcohol) films, the average pore size increases at high RH because of partial cleavage of inter-molecular hydrogen bonds, resulting in high $\mathrm{P}-\mathrm{O}_{2}$ values [46]. 


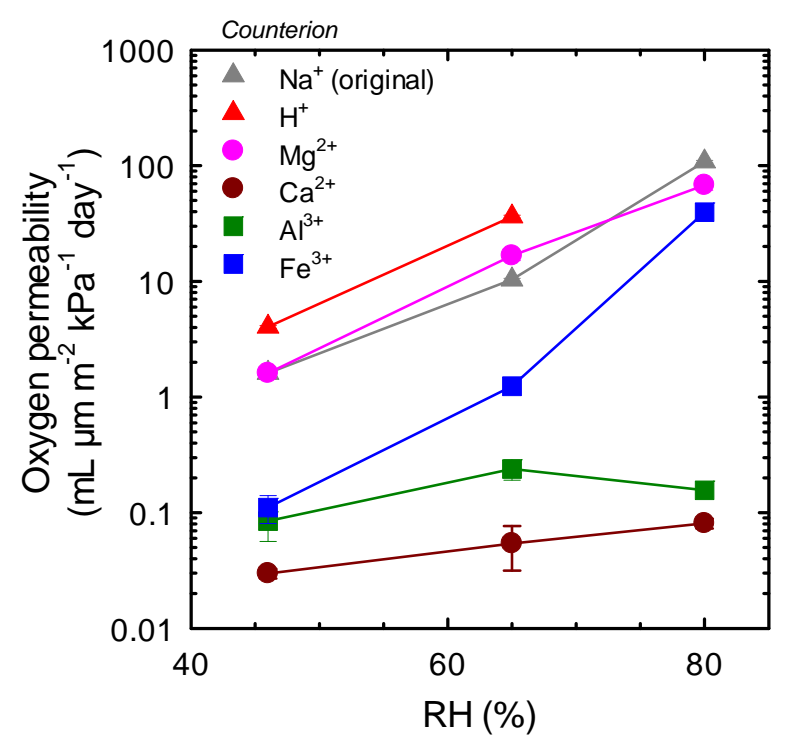

Fig. 7. Oxygen permeability of the original TOCN-COONa and ion-exchanged TOCN-COOM films under various RH conditions.

The excellent oxygen barrier performance of TOCN-COOCa and TOCN-COOAl films shown in Figure 7 cannot be explained simply in terms of their film densities or moisture contents at $23{ }^{\circ} \mathrm{C}$ and $50 \% \mathrm{RH}$ (Table 1) or from the results of the wet tensile properties (Figure 6). The TOCN-COOCa film did not have the highest Young's modulus or tensile strength in the water-swollen state, and also did not have the lowest moisture content at $23{ }^{\circ} \mathrm{C}$ and $50 \% \mathrm{RH}$. Thus, the interfibrillar cross-linkages with $\mathrm{Ca}^{2+}$ in the film are not completely stable when the film is fully soaked in water. However, the TOCN-COOCa film density was $1.68 \mathrm{~g} / \mathrm{cm}^{3}$ and the highest in the TOCN-COOM films examined in this study, indicating that this high film density may have caused the highest oxygen barrier performance at $80 \% \mathrm{RH}$ (Table 1).

This explanation, however, does not completely explain the results for the TOCN-COOAl and TOCN-COOFe films. Although the TOCN-COOAl film had a density of $1.44 \mathrm{~g} / \mathrm{cm}^{3}$ at $23{ }^{\circ} \mathrm{C}$ and $50 \% \mathrm{RH}$ lower than that of the TOCN-COOFe film $\left(1.58 \mathrm{~g} / \mathrm{cm}^{3}\right)$, the former film had a significantly low $\mathrm{P}-\mathrm{O}_{2}$ value at $80 \% \mathrm{RH}$. The relatively high ratio of protonated 
carboxyl groups in the TOCN-COOFe films may have caused the high $\mathrm{P}_{-} \mathrm{O}_{2}$ value at $80 \% \mathrm{RH}$ (Table 1). Moreover, it may be possible that magnesium, iron and aluminum carboxylate groups in the corresponding TOCN-COOM films contained some hydrated structures, which may influence the $\mathrm{P}-\mathrm{O}_{2}$ values under high $\mathrm{RH}$ conditions. Thus, there is no suitable mechanism at present that can explain all the results in Figure 7. Nevertheless, it is significant to conclude from the obtained results that the TOCN-COOCa films had high oxygen barrier performance over a wide $\mathrm{RH}$ range. Moreover, the ion-exchange procedure is quite simple: soaking the original TOCN-COONa film in aqueous $\mathrm{CaCl}_{2}$ solutions, washing with water and then drying, to form TOCN-COOCa films.

\section{Conclusion}

Water resistant nanocellulose films were prepared through a simple ion-exchange of the original TOCN-COONa film. The original sodium counterions of the carboxylate groups present on TOCN surfaces were exchanged with multivalent metal ions by soaking the TOCN-COONa film in aqueous metal chloride solutions, washing with water and drying. The TOCN-COOM films retained their high optical transmittances of $\sim 80 \%$ at $600 \mathrm{~nm}$ and high tensile strengths and Young's moduli at $23{ }^{\circ} \mathrm{C}$ and $50 \%$ RH. The wet TOCN-COOAl and TOCN-COOFe films had high Young's moduli of $>3 \mathrm{GPa}$ and high tensile strengths of $30-40$ $\mathrm{MPa}$, showing that the trivalent metal ions are effective in improving the wet tensile strength of TOCN films. The $\mathrm{P}_{-} \mathrm{O}_{2}$ values of the TOCN-COOM films increased under humid conditions. However, the $\mathrm{P}-\mathrm{O}_{2}$ values of the TOCN-COOCa and TOCN-COOAl films were extremely low, $\sim 0.1 \mathrm{~mL} \mu \mathrm{m} \mathrm{m} \mathrm{may}^{-1} \mathrm{kPa}^{-1}$, at $80 \% \mathrm{RH}$, compared to previously reported nanocellulose films. These low $\mathrm{P}-\mathrm{O}_{2}$ values can be explained in terms of the formation of interfibrillar cross-linkages with multivalent metal ions in the films stable to humid conditions. The results obtained in this study would expand the application fields of TOCN films under 
various humid and wet conditions.

\section{Acknowledgments}

This research was supported by Core Research for Evolutional Science and Technology (CREST) of Japan Science and Technology Agency (JST) and Grants-in-Aid for Scientific Research (No. 26-6871) from the Japan Society for the Promotion of Science (JSPS).

\section{References}

[1] D. Klemm, F. Kramer, S. Moritz, T. Lindström, M. Ankerfors, D. Gray, A. Dorris, Nanocelluloses: A new family of nature-based materials. Angw. Chem. Int. Ed. 50 (2011) 5438-5466.

[2] A. Isogai, T. Saito, H. Fukuzumi, TEMPO-oxidized cellulose nanofibers. Nanoscale 3 (2011) 71-85.

[3] R.J. Moon, A. Martini, J. Naim, J. Simonsen, J. Youngblood, Cellulose nanomaterials review: Structure, properties and nanocomposites. Chem. Soc. Rev. 40 (2011) 39413994.

[4] K. Syverud, P. Stenius, Strength and barrier properties of MFC films. Cellulose 16 (2009) 75-85.

[5] Y. Okahisa, A. Yoshida, S. Miyaguchi, H. Yano, Optically transparent wood-cellulose nanocomposite as a base substrate for flexible organic light-emitting diode displays. Compos. Sci. Technol. 69 (2009) 1958-1961.

[6] H. Fukuzumi, T. Saito, T. Iwata, Y. Kumamoto, A. Isogai, Transparent and high gas barrier films of cellulose nanofibers prepared by TEMPO-mediated oxidation. Biomacromolecules 10 (2009) 162-165.

[7] H. Koga, M. Nogi, N. Komoda, T.T. Nge, T. Sugahara, K. Suganuma, Uniformly connected conductive networks on cellulose nanofiber paper for transparent paper electronics. NPG Asia Mater. 6 (2014) e93. 
[8] A.J. Benitez, J. Torres-Rendon, M. Poutanen, A. Walther, Humidity and multiscale structure govern mechanical properties and deformation modes in films of native cellulose nanofibrils. Biomacromolecules 14 (2013) 4497-4506.

[9] K. Prakobna, C. Terenzi, Q. Zhou, I. Furo, L.A. Berglund, Core-shell cellulose nanofibers for biocomposites - Nanostructural effects in hydrated state. Carbohydr. Polym. 125 (2015) 92-102.

[10] C. Aulin, M. Gällstedt, T. Lindström, Oxygen and oil barrier properties of microfibrillated cellulose films and coatings. Cellulose 17 (2010) 559-574.

[11] M. Martinez-Sanz, A. Lopez-Rubio, J.M. Lagaron, High-barrier coated bacterial cellulose nanowhiskers films with reduced moisture sensitivity. Carbohydr. Polym. 98 (2013) 1072-1082.

[12] S. Belbekhouche, J. Bras, G. Siqueira, C. Chappey, L. Lebrun, B. Khelifi, S. Marais, A. Dufresne, Water sorption behaviour and gas barrier properties of cellulose whiskers and microfibrils films. Carbohydr. Polym. 83 (2011) 1740-1748.

[13] N. Pahimanolis, A. Salminen, P.A. Penttilä, J.T. Korhonen, L.-S. Johonsson, J. Ruokolainen, R. Serimaa, J. Seppälä, Nanofibrillated cellulose/carboxymethyl cellulose composite with improved wet strength. Cellulose 20 (2013) 1459-1468.

[14] K. Prakobna, S. Galland, L.A. Berglund, High-performance and moisture-stable cellulose-starch nanocomposites based on bioinspired core-shell nanofibers. Biomacromolecules 16 (2015) 904-912.

[15] M.S. Toivonen, S. Kurki-Suonio, F.H. Schacher, S. Hietala, O.J. Rojas, O. Ikkala, Water-resistant, transparent hybrid nanopaper by physical cross-linking with chitosan. Biomacromolecules 16 (2015) 1062-1071.

[16] M. Hakalahti, A. Salminen, J. Seppälä, T. Tammelin, T. Hänninen, Effect of Interfibrillar PVA bridging on water stability and mechanical properties of TEMPO/ $\mathrm{NaClO}_{2}$ oxidized cellulosic nanofibril films. Carbohydr. Polym. 126 (2015) $78-82$.

[17] B. Wang, J.G. Torres-Rendon, J. Yu, Y. Zhang, A. Walther, Aligned bioinspired 
cellulose nanocrystal-based nanocomposites with synergetic mechanical properties and improved hygromechanical performance. ACS Appl. Mater. Interfaces 7 (2015) 45954607.

[18] J.-F. Sassi, H. Chanzy, Ultrastructural aspects of the acetylation of cellulose. Cellulose 2 (1995) 111-127.

[19] H. Sehaqui, T. Zimmermann, P. Tingaut, Hydrophobic cellulose nanopaper through a mild esterification procedure. Cellulose 21 (2014) 367-382.

[20] K. Xhanari, K. Syverud, G. Chinga-Carrasco, K. Paso, P. Stenius, Reduction of water wettability of nanofibrillated cellulose by adsorption of cationic surfactants. Cellulose 18 (2011) 257-270.

[21] R.K. Johnson, A. Zink-Sharp, W. Glasser, Preparation and characterization of hydrophobic derivatives of TEMPO-oxidized nanocelluloses. Cellulose 18 (2011) 1599-1609.

[22] S. Fujisawa, T. Saito, A. Isogai, Nano-dispersion of TEMPO-oxidized cellulose/aliphatic amine salts in isopropyl alcohol. Cellulose 19 (2012) 459-466.

[23] M. Salajokova, L.A. Berglund, Q. Zhou, Hydrophobic cellulose nanocrystals modified with quaternary ammonium salts. J. Mater. Chem. 22 (2012) 19798-19805.

[24] M. Shimizu, T. Saito, H. Fukuzumi, A. Isogai, Hydrophobic, ductile, and transparent nanocellulose films with quaternary alkylammonium carboxylates on nanofibril surfaces. Biomacromolecules 15 (2014) 4320-4325.

[25] M. Shimizu, H. Fukuzumi, T. Saito, A. Isogai, Preparation and characterization of TEMPO-oxidized cellulose nanofibrils with ammonium carboxylate groups. Int. J. Biol. Macromol. 59 (2013) 99-104.

[26] R. Shinoda, T. Saito, Y. Okita, A. Isogai, Relationship between length and degree of polymerization of TEMPO-oxidized cellulose nanofibrils. Biomacromolecules 13 (2012) 842-849.

[27] K.M. Lin, Y.Y. Chen, Improvement of electrical properties of sol-gel derived ZnO:Ga films by infrared heating method. J. Sol-Gel Sci. Technol. 51 (2009) 51, 215-221. 
[28] T. Saito, A. Isogai, A novel method to improve wet strength of paper. Tappi J. 4 (2005) $3-8$.

[29] T. Saito, A. Isogai, Ion-exchange behaviour of carboxylate groups in fibrous cellulose oxidized by the TEMPO-mediated system. Carbohydr. Polym. 61 (2005) 183-190.

[30] H. Fukuzumi, T. Saito, Y. Okita, A. Isogai, Thermal stabilization of TEMPO-oxidized cellulose. Polym. Degrad. Stab. 95 (2010) 1502-1508.

[31] S. Fujisawa, Y. Okita, H. Fukuzumi, T. Saito, A. Isogai, Preparation and characterization of TEMPO-oxidized cellulose nanofibril films with free carboxyl groups. Carbohydr. Polym. 84 (2011) 579-583.

[32] H. Dong, J.F. Snyder, K.S. Williams, J.W. Andzelm, Cation-induced hydrogels of cellulose nanofibrils with tuneable moduli. Biomacromolecules 14 (2013) 3338-3345.

[33] H. Fukuzumi, S. Fujisawa, T. Saito, A. Isogai, Selective permeation of hydrogen gas using cellulose nanofibril film. Biomacromolecules 14 (2013) 1705-1709.

[34] J.N. Israelachvili, Intermolecular and Surface Forces: 3rd Ed; Asakura Publishing: Tokyo (2013) Chapter 4, 18, pp 65, 402-418.

[35] J.C. Grunlan, A. Grigorian, C.B. Hamilton, A.R. Mehrabi, Effect of clay concentration on the oxygen permeability and optical properties of a modified poly(vinyl alcohol). J. Appl. Polym. Sci. 93 (2004) 1102-1109.

[36] C. Aulin, G. Salazar-Alvarez, T. Lindström, High strength, flexible and transparent nanofibrillated cellulose-nanoclay biohybrid films with tuneable oxygen and water vapour permeability. Nanoscale 4 (2012) 6622-6628.

[37] M. Österberg, J. Vartiainen, J. Lucenius, U. Hippi, J. Seppälä, R. Serimaa, J. Laine, A fast method to produce strong NFC films as a platform for barrier and functional materials. ACS Appl. Mater. Interfaces 5 (2013) 4640-4647.

[38] P.A. Larsson, L.A. Berglund, L Wågberg, Ductile all-cellulose nanocomposite films fabricated from core-shell structured cellulose nanofibrils. Biomacromolecules 15 (2014) 2218-2223. 
[39] S. Galland, Y. Leterrier, T. Nardi, C.J.G. Plummer, J.A.E. Manson, L.A. Berglund, UV-cured cellulose nanofiber composites with moisture durable oxygen barrier properties. J. Appl. Polym. Sci. 131 (2014) 40604.

[40] J. Lange, Y. Wyser, Recent innovations in barrier technologies for plastic packaging A review. Packag. Technol. Sci. 16 (2003) 149-158.

[41] T. Nakagawa, The barrier properties of packaging materials; Packaging Science \& Technology, Tokyo (2003) pp 79-98.

[42] M. Muramatsu, M. Okura, K. Kuboyama, T. Ougizawa, T. Yamamoto, Y. Nishihara, Y. Saito, K. Ito, K. Hirata, Y. Kobayashi, Oxygen permeability and free volume hole size in ethylene-vinyl alcohol copolymer film: Temperature and humidity dependence. Radiat. Phys. Chem. 68 (2003) 561-564.

[43] Q. Yang, H. Fukuzumi, T. Saito, A. Isogai, L. Zhang, Transparent cellulose films with high gas barrier properties fabricated from aqueous alkali/urea solutions. Biomacromolecules 12 (2011) 2766-2771.

[44] H. Fukuzumi, S. Fujisawa, T. Saito, A. Isogai, Selective permeation of hydrogen gas using cellulose nanofibril film. Biomacromolecules 14 (2013) 1705-1709.

[45] U. Edlund, Y. Yu, Y. Zhu Ryberg, R. Krause-Rehberg, A.C. Albertsson, Positron lifetime reveals the nano level packing in complex polysaccharide-rich hydrolysate matrixes. Anal. Chem. 84 (2012) 3676-3681.

[46] W. Zhou, Z. Chen, N. Oshima, K. Ito, B.E. O’Rourke, R. Kuroda, R. Suzuki, H. Yanagishita, T. Tsutsui, A. Uedono, N. Hayashizaki, N. In-situ characterization of free-volume holes in polymer thin films under controlled humidity conditions with an atmospheric positron probe microanalyzer. Appl. Phys. Lett. 101 (2012) 014102. 


\section{Graphical abstract}

Water-resistant and high oxygen-barrier nanocellulose films with interfibrillar cross-linkages formed through multivalent metal ions

Michiko Shimizu, Tsuguyuki Saito, Akira Isogai*

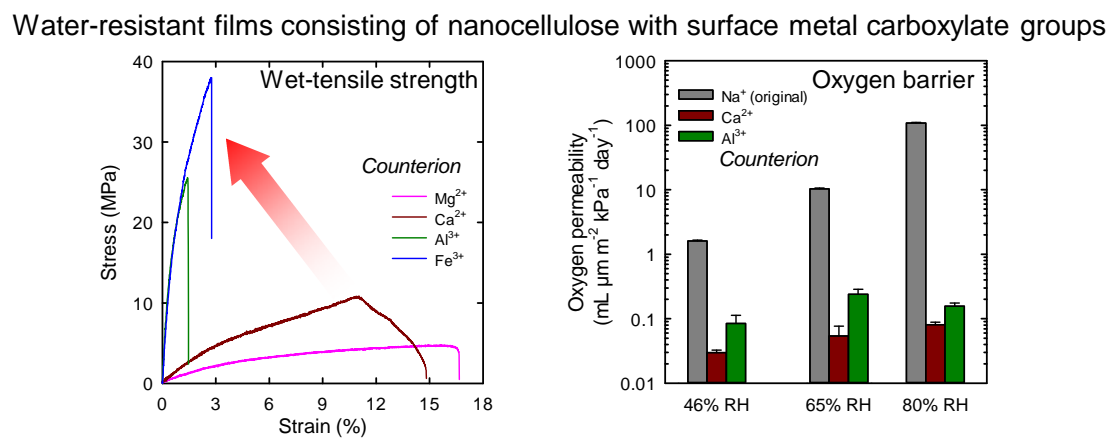

